\title{
Fuzzy Multi-Criteria Decision-Making for Information Security Risk Assessment
}

\author{
A. Shameli-Sendi ${ }^{*}, 1$, M. Shajari ${ }^{2}$, M. Hassanabadi ${ }^{2}$, M. Jabbarifar ${ }^{1}$ and M. Dagenais ${ }^{1}$ \\ ${ }^{I}$ Computer Engineering Department, Ecole Polytechnique de Montreal, Montreal, Canada \\ ${ }^{2}$ Computer and Information Technology Engineering Department, Amirkabir University of Technology, Tehran, Iran
}

\begin{abstract}
Risk assessment is a major part of the ISMS process. In a complex organization which involves a lot of assets, risk assessment is a complicated process. In this paper, we present a practical model for information security risk assessment. This model is based on multi-criteria decision-making and uses fuzzy logic. The fuzzy logic is an appropriate model to assess risks and represents the practical results. The proposed risk assessment is a qualitative approach according to ISO/IEC 27005 standard. Main objectives and processes of business have been considered in this model and assessment of risk has been done in managerial and operational levels. This model was performed completely in the information technology section of a supply chain management company and the results show its efficiency and reliability.
\end{abstract}

Keywords: Risk assessment, information security, fuzzy logic, multi-criteria decision-making, ISO/IEC 27005.

\section{INTRODUCTION}

Today, many organizations and companies use information systems and network frameworks on a large scale, thus IT dependency is increasing daily. Security is one of the most important issues for the stability and development of these systems. Therefore, most organizations invest in this area and are establishing Information Security Management Systems (ISMS). Although many organizations understand the importance of security, many could not find an efficient solution to implement an ISMS.

The main process of an ISMS implementation is risk assessment [1,2]. Risk assessment provides organizations with an accurate evaluation of the risks to their assets. It can help them prioritize and develop a comprehensive strategy to reduce risks. Information security risk assessment does not have an old history. There are some standards and methodologies for risk assessment, such as NIST and ISO27001, but while they explain general principles and guidelines, they do not give any implementation details [3]. This may cause ambiguities to the users [4]. A practical model for information security risk assessment is presented in this paper; it can be used by various organizations. Considering the limitations of quantitative approaches, this model recommends a qualitative method based on expert opinions and fuzzy techniques for information security risk assessment. The relevant knowledge from human experts is stored as rules database in order to apply fuzzy logic and infer an overall numerical value [5].

The paper is organized as follows: first, we will investigate earlier work, and several existing methods for

*Address correspondence to this author at the Computer Engineering Department, Ecole Polytechnique de Montreal, P.O. Box 6079, Succ. Downtown, Montreal, Quebec, H3C 3A7, Canada; Tel: 1514340 4711; E-mail: alireza.shameli-sendi@polymtl.ca risk assessment will be introduced. Fuzzy modeling is illustrated in Section 3. The proposed model will be discussed in Section 4. Experimental results are presented in Section 5. Section 6 concludes the paper.

\section{RELATED WORK}

Multi-criteria decision-making (MCDM) for risk assessment have been applied to many issues such as risk of E-business development, software development, groundwater contamination, forestry, health centers and etc. Different methods have been used in determining the level of risk, most often based on measuring the impact of risk. Likewise some proposed techniques use predefined rulebased techniques. Information security risk assessment has a recent history, and related standards and methodologies are in progress.

Zhao et al. [6] evaluated network security risk by using probabilities, impact severity, AHP techniques and Shannon entropy technique. Decisions were made using fuzzy logic through linguistic variables. Shannon entropy technique was also applied in weighting decision matrix. Shannon entropy technique is useful to prioritize risks but cannot be used in calculations to determine the risk level.

Guan et al. [7] assessed risks according to the likelihood and impact factors of threats. In this method, risk factors are determined according to standard ISO17799 categorization. Then, it is assumed that determining the likelihood of each risk is similar to determining the weights in pairwise comparisons in the AHP method. Based on this view, the likelihood or weight of each risk factor is being determined using expert opinions. On the other hand, the vulnerability of each Information asset for each risk factor is considered equal to its impact severity, which takes its relative value from experts through linguistic variables. An important point in this paper is its assumption which should be thought about. The causes of similarity between weights of risk 
factors and their occurrence likelihood have not been defined in this paper. Also, the reason for considering the vulnerability of an asset to a risk factor as its impact severity is not clear. As mentioned in [1], the vulnerability is assumed to be a determining factor of likelihood of risk, rather than its severity impact.

Hwang and Yoon [8] proposed the simple additive weight (SAW) method which is the most widely used in multi-criteria decision-making. This technique obtains a weighted sum of the performance ratings of each alternative under all attributes. In the first step of this method, it scales the values of all attributes to make them comparable and eventually it sums up the values of the all attributes for each alternative [9].

Wang and Elhag [10] proposed a fuzzy TOPSIS method based on alpha level sets and applied it in bridge risk assessment. In this example, the likelihood and impact of different threats are assumed in linguistic variable forms and then are applied in bridge risk assessment by multiplying their related fuzzy values. Likewise, four effective criterion on impact severity are introduced. Experts propose their opinions in the form of these four criterions and eventually the severity impact is calculated.

Haslum et al. [11] proposed a fuzzy model for online risk assessment in networks. The main contribution of their paper is the fuzzy logic controllers. They were developed to quantify the various risks based on a number of variables derived from the inputs from various components.

Shameli-Sendi et al. [12] presented the FEMRA model, which uses fuzzy expert systems to assess risk in organizations. The risk assessment varies considerably with the context, the metrics used as dependent variables, and the opinions of the persons involved. Asset classification has a very important role in information security management. They have designed a security cube, which is a combination of valuable and important assets from a security perspective of the organization, and the Zachman model.

The main contributions of this work is that the assessment process is divided into two levels: managerial and operational. In operational level, with respect to regular categorization of Information Systems in organizations, some domains are defined and relative threats to each domain are determined. Then likelihood and impact of threat occurrence are assessed and calculated using MCDM and with each realm experts. The distinct approach of this model, compared with previous models, is that for determining likelihood and impact of each threat, effective criterions are considered for their measurement, and experts present their opinions with respect to these criterions. Therefore, assessment of likelihood and impact is based on effective criterions. It leads us to increasing accuracy and reliability of the results.

Another advantage of this model, compared with others, is that assessment of risks is not only done technically, but also the importance of Information Systems is taken into account with respect to goal and mission of organization and main procedures of business.

\section{FUZZY MODEL}

Human experts rely on their experience and judgement to estimate the risk. The concept of risk has a different meaning for different people. Fuzzy model is the best model to tackle this weakness. In this section, some definitions and properties used in this paper are introduced:

Definition 1) There are different fuzzy numbers, the most interesting to calculate being triangular (see Fig. 1) and trapezoidal fuzzy numbers.

Definition 2) Fuzzy set $\bar{A}=(a, b, c)$ on real number domain is called a triangular fuzzy number if its membership function has the specifications:

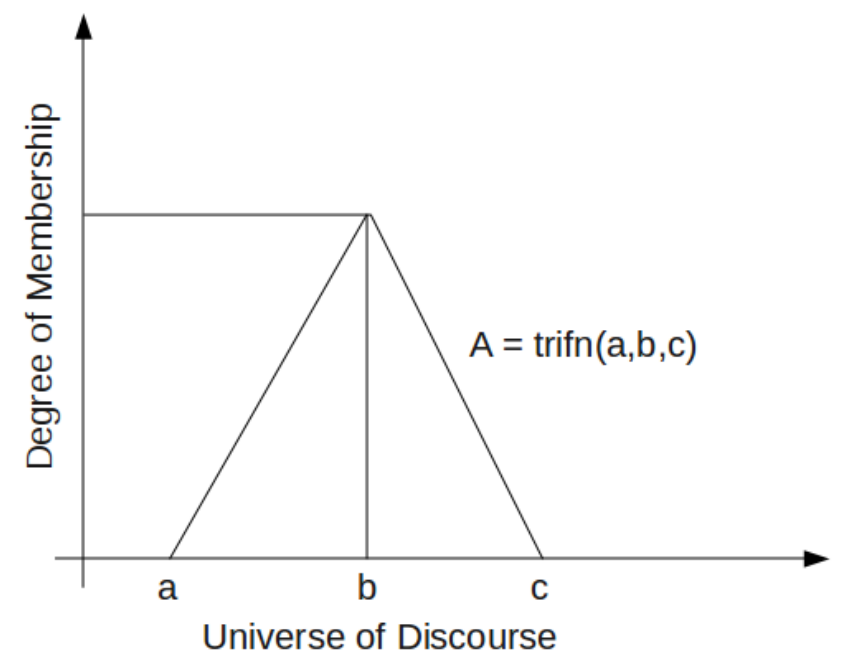

Fig. (1). Triangular fuzzy number and its membership function.

$$
\gamma(X)= \begin{cases}\frac{(x-a)}{(b-a)} & \text { if } a \leq x \leq b \\ \frac{(x-c)}{(b-c)} & \text { if } b \leq x \leq c \\ 0 & \text { otherwise }\end{cases}
$$

Property 1) Given two positive triangular fuzzy numbers $A$ and $B$, the main operations on them can be expressed as follow [13]:

$$
\begin{aligned}
& \bar{A}=(a, b, c) \\
& \bar{B}=(d, e, f) \\
& \bar{A}+\bar{B}=(a+d, b+e, c+f) \\
& \bar{A}-\bar{B}=(a-f, b-e, c-d) \\
& \bar{A} \otimes \bar{B}=(a d, b e, c f) \\
& \bar{A} \\
& \overline{\bar{B}}=\left(\frac{a}{f}, \frac{b}{e}, \frac{c}{f}\right) \\
& K \otimes \bar{B}=(K a, K b, K c)
\end{aligned}
$$

Property 2) Yao and Chiang [14] compared Centroid and Signed distance methods and the results show that signed 
distance produces better results for defuzzification of triangular fuzzy numbers. The signed distance of triangular fuzzy number $\bar{A}=(a, b, c)$ is defined as follows and is used for defuzzification [15]:

$A=\frac{a+2 \mathrm{~b}+c}{4}$

Definition 3) In this model, linguistic variables are used to get experts opinion for weights of criteria and rate of alternatives, with respect to various criteria whose fuzzy equivalent is as follows [16]:

Table 1. Linguistic Variables and Fuzzy Equivalent for the Importance Weight of Each Criterion

\begin{tabular}{|c|c|}
\hline Linguistic Variables & Fuzzy Triangular \\
\hline \hline Very low (VL) & $(0,0,0.1)$ \\
\hline Low (L) & $(0,0.1,0.3)$ \\
\hline Medium low (ML) & $(0.1,0.3,0.5)$ \\
\hline Medium (M) & $(0.3,0.5,0.7)$ \\
\hline Medium high (MH) & $(0.5,0.7,0.9)$ \\
\hline High $(\mathrm{H})$ & $(0.7,0.9,1.0)$ \\
\hline Very high $(\mathrm{VH})$ & $(0.9,1.0,1.0)$ \\
\hline
\end{tabular}

Table 2. Linguistic Variables and Fuzzy Number for the Ratings

\begin{tabular}{|c|c|}
\hline Linguistic Variables & Fuzzy Triangular \\
\hline \hline Very poor (VP) & $(0,0,1)$ \\
\hline Poor (P) & $(0,1,3)$ \\
\hline Medium poor (MP) & $(1,3,5)$ \\
\hline Fair (F) & $(3,5,7)$ \\
\hline Medium good (MG) & $(5,7,9)$ \\
\hline Good (G) & $(7,9,10)$ \\
\hline Very good (VG) & $(9,10,10)$ \\
\hline
\end{tabular}

\section{PROPOSED MODEL}

Multi-criteria decision-making is a method based on decision making tables where the value of each alternative in decision making is determined by experts. The aim of multicriteria decision-making techniques is to rate and determine the priority among different alternatives.

MCDM uses various methods, the most famous and widely used being: AHP, TOPSIS and SAW.

As mentioned, the AHP method [7] is based on pairwise comparisons and is very accurate, but cannot easily be accepted by experts. Also, in the entropy technique, if all alternatives in a criterion have "very high" value, it leads to high decrease on weight of that criterion. In this work, we are looking for actual value of alternatives and the relative value to the "very high" case should be used for determining the value of that alternative.
In TOPSIS [10], the chosen alternative should be as close as possible to the positive ideal and as far away as possible from the negative ideal solution. Therefore, if we apply the TOPSIS technique for assessing risk, it prioritizes and ranks the risks, but this is not our goal. Thus, the TOPSIS technique cannot be used directly in our model.

The Simple Additive Weighting method (SAW) [8] is the most popular approach for multi-criteria decision-making. In SAW technique, determining the weight of criteria in decision making tables is done according to answerers' opinion. Generally, this task is done either according to values of decision making tables like for the techniques of Shanon entropy and LINMAP, or it is directly determined by the answerers like pairwise comparisons or assigning weights directly by experts.

Since a practical model for any organization is our goal, the SAW technique was chosen for implementation. Also, since risk assessment is in a domain of ambiguous topics, fuzzy logic is appropriate for evaluation in uncertain subjects, and, by using it, experts can propose their opinion in a linguistic variable form like "very high", "low", etc.

The assessment process in the proposed model is divided into two levels: managerial and operational. Then, likelihood and impact of threat occurrence are assessed and calculated using MCDM and with each realm experts. The importance of each domain of Information systems is taken into account with respect to goals and mission of organization, and main procedures of business.

\subsection{Assessment in Managerial Level}

In this level, different domains of Information Technology (IT) assets are identified based on standard ISO/IEC 27005:

- Network services and communication infrastructures such as network software, hardware and connections.

- Hardware such as server and client computers.

- Application software such as financial system, production system and human recourse information systems.

- Databases.

- Knowledge and skills of the Information Technology personnel.

- $\quad$ Security equipment such as firewall and Antivirus.

- Communication services such as Email.

- Informational services such as Intranet (Web).

- Digital document such as technical plans and future designs.

Managers of Information Technology departments and other senior and intermediate managers, who are familiar with Information Systems, determine the importance of each asset domain by using SAW technology and the four main criterions: 1) the effect on the goals and mission of the organization 2) the effect on the main procedures of the 
organization 3) the effect on the production quality and organization services 4 ) the effect on customer relationship and satisfaction.

\subsection{Assessment in Operational Level}

In this level, in the first step, threats relative to each domain are determined based on [17] and appendixes B and $\mathrm{C}$ of standard ISO/IEC 27005 [18]. The occurrence likelihood of threats and their impact intensity are two main factors in risk level estimation. Therefore, in each domain, two decision making tables are made to evaluate these two factors. Then, each expert determines the importance of each criterion and the value of each alternative in relation to each criterion using linguistic variables. Eventually, using the SAW technique, the likelihood and impact of each threat will be clarified and the risk level is calculated by multiplying these two factors. The following table shows the effective criterions for determining the likelihood and impact intensity of threats:

Table 3. Effective Criterions for Determining the Likelihood and Impact Intensity of Threats

\begin{tabular}{|c|c|}
\hline Effective Criterion & Effective Criterion \\
\hline \hline for impact intensity & for occurrence likelihood \\
\hline Financial cost & Attraction of information asset \\
\hline Time cost (lost) & Simplicity of gaining profit \\
\hline Credit cost & Vulnerability \\
\hline Human cost & Existing control \\
\hline & History of threats \\
\hline
\end{tabular}

\subsection{Execution Stages} 19]):

To implement this model, 11 steps have to be done [9,

Step 1) Obtain expert opinions in the form of linguistic variables about the importance of each domain of Section 4.1. It must be done based on decision making table (Table 1) that shows the weight of each criteria.

Step 2) Obtain expert opinions in the form of linguistic variables to evaluate the importance of the criteria.

Step 3) Obtain expert opinions of each domain about of likelihood and impact of each threat related to each domain in the form of linguistic variables (Table 2).

Step 4) Replace linguistic variables with fuzzy variables based on Tables 2 and 3. Merge all expert opinions in each domain and establish a decision making matrix. $\tilde{x}_{i j}$ and $\tilde{w}_{j}$ are triangular fuzzy numbers and assume that our decision group has k persons:

$$
\begin{aligned}
& \tilde{x}_{i j}=\left(a_{i j}, b_{i j}, c_{i j}\right) \\
& \tilde{w}_{j}=\left(w_{j l}, w_{j 2}, w_{j 3}\right) \\
& \tilde{x}_{i j}=\frac{1}{K}\left[\tilde{x}_{i j}^{1}(+) \tilde{x}_{i j}^{2}(+) \ldots(+) \tilde{x}_{i j}^{k}\right] \\
& \tilde{w}_{j}=\frac{1}{K}\left[\tilde{w}_{j}^{1}(+) \tilde{w}_{j}^{2}(+) \ldots(+) \tilde{w}_{j}^{k}\right]
\end{aligned}
$$

$$
\begin{aligned}
& \tilde{D}=\left[\begin{array}{llll}
\tilde{x}_{11} & \tilde{x}_{12} & \cdots & \tilde{x}_{1 \mathrm{n}} \\
\tilde{x}_{21} & \tilde{x}_{22} & \cdots & \tilde{x}_{2 \mathrm{n}} \\
\vdots & \vdots & \cdots & \vdots \\
\tilde{x}_{m 1} & \tilde{x}_{m 2} & \cdots & \tilde{x}_{m n}
\end{array}\right] \\
& \tilde{W}=\left[\tilde{w}_{1}, \tilde{w}_{2}, \ldots, \tilde{w}_{n}\right]
\end{aligned}
$$

Step 5) Linear normalization of consolidated matrix through the following relationship (category B is related to incremental criteria and category $\mathrm{C}$ is related to decremental criteria):

$$
\begin{aligned}
& \tilde{r}_{i j}=\left\{\begin{array}{l}
\frac{a_{i j}}{c_{j}}, \frac{b_{i j}}{c_{j}}, \frac{c_{i j}}{c_{j}} \quad \text { if } j \in B \\
\frac{a_{j}^{-}}{c_{i j}}, \frac{a_{j}^{-}}{b_{i j}}, \frac{a_{j}^{-}}{a_{i j}} \quad \text { if } j \in C
\end{array}\right. \\
& c_{j}=\max \quad c_{i j} \quad \text { if } \quad j \in B \\
& c_{j}^{-}=\min \quad a_{i j} \quad \text { if } \quad j \in C
\end{aligned}
$$

Step 6) Deffuzification of combined weights through signed distance method and normalization through the following formula:

$w_{j}=\frac{w_{j}}{\sum_{j} w_{j}}$

Step 7) Calculate weighty matrix:

$\left[\begin{array}{llll}\tilde{x}_{11} & \tilde{x}_{12} & \cdots & \tilde{x}_{1 \mathrm{n}} \\ \tilde{x}_{21} & \tilde{x}_{22} & \cdots & \tilde{x}_{2 \mathrm{n}} \\ \vdots & \vdots & \cdots & \vdots \\ \tilde{x}_{m 1} & \tilde{x}_{m 2} & \cdots & \tilde{x}_{m n}\end{array}\right] *\left[\begin{array}{l}w_{1} \\ w_{2} \\ \vdots \\ w_{n}\end{array}\right]$

Step 8) Multiply the fuzzy values of likelihood and impact of each threat and calculate the probability of the threat occurring in each domain.

Step 9) Deffuzification of fuzzy values by Signed Distance method for each threat and calculation of the risk level for each domain.

Step 10) Calculate the overall risk level of organization by multiplying the risk level of threat with every domain importance Coefficient.

Step 11) Match the result with Table 4 for determining how to deal with risks.

All the values of Table 4 were derived through the implementation of the 10-step risk assessment process for these individual ranges.

\section{EXPERIMENTAL RESULTS}

To verify the efficiency of the proposed model, it has been implemented in the IT section of a supply chain management company. In our evaluation, 81 threats $[1,20$, 
21] and 9 domains had been defined in advance. At first, to determine the importance of each domain, experts proposed their opinion in the form of linguistic variables, according to the managerial and operational levels. Table 5 illustrates the importance of each domain (Step1). The results are reasonable, based on the business process of this company and the relationship with its suppliers. Table 6 illustrates the threats related to the digital documents domain. We continue the presentation of our results with this domain and eventually with the results of all domains (Tables 21-28).

Table 4. Estimated Levels of Risk Related to Different Scenarios

\begin{tabular}{|c|c|}
\hline Estimated Levels of Risk & Range \\
\hline \hline Low-Low & 0.00 \\
\hline Low-Medium & 0.0670683 \\
\hline Low-High & 1.9509554 \\
\hline Medium & 14.0392099 \\
\hline High-Low & 53.9383740 \\
\hline High-Medium & 132.7093795 \\
\hline High-High & 205.7530127 \\
\hline
\end{tabular}

Table 5. Relative Importance of Different Domains in the Organization

\begin{tabular}{|l|c|c|c|}
\hline \multicolumn{1}{|c|}{ Domain } & $\begin{array}{c}\text { Initial } \\
\text { Weight }\end{array}$ & $\begin{array}{c}\text { Normalized } \\
\text { Weight }\end{array}$ & $\begin{array}{c}\text { Normalized } \\
\text { Weight *1000 }\end{array}$ \\
\hline \hline $\begin{array}{l}\text { Communication } \\
\text { services }\end{array}$ & 0.8594 & 0.137776135 & 137.78 \\
\hline $\begin{array}{l}\text { Network services and } \\
\text { communication } \\
\text { infrastructures }\end{array}$ & 0.8108 & 0.129984377 & 129.98 \\
\hline Informational services & 0.774 & 0.124084642 & 124.08 \\
\hline Database & 0.76515 & 0.122665272 & 122.67 \\
\hline Hardware & 0.67612 & 0.108392263 & 108.39 \\
\hline $\begin{array}{l}\text { Knowledge and skills } \\
\text { of the personnel }\end{array}$ & 0.65733 & 0.105380652 & 105.38 \\
\hline Application software & 0.64724 & 0.103762883 & 103.76 \\
\hline Security equipments & 0.52618 & 0.084354874 & 84.35 \\
\hline Digital documents & 0.52146 & 0.083598903 & 83.6 \\
\hline
\end{tabular}

Table 6. Digital Documents Threats

\begin{tabular}{|c|c|}
\hline & Name \\
\hline \hline $\mathrm{T} 1$ & Unauthorized access \\
\hline $\mathrm{T} 2$ & Unauthorized copy or send \\
\hline $\mathrm{T} 3$ & Unauthorized edit or delete \\
\hline
\end{tabular}

In the operational level, our goal is to indicate the likelihood and impact of each threat in each domain and, eventually, calculate the risk level. As Tables 7 and 8 illustrate, in the next step, experts compare the criterions related to likelihood and impact of threats (Step 2). The experts use the linguistic rating variables to assess the rating of threats with respect to likelihood and impact criterions as shown in Table $\mathbf{9}$ (Step3). Tables $\mathbf{1 0}$ and $\mathbf{1 1}$ show the fuzzy
Table 7. Importance Weight of Criteria Related to Likelihood of Threats

\begin{tabular}{|l|c|c|}
\hline & DM1 & DM2 \\
\hline \hline C1: Attraction of information asset & $\mathrm{H}$ & $\mathrm{H}$ \\
\hline C2: Simplicity of gaining profit & $\mathrm{H}$ & $\mathrm{MH}$ \\
\hline C3: Vulnerability & $\mathrm{MH}$ & $\mathrm{MH}$ \\
\hline C4: Existing control & $\mathrm{ML}$ & $\mathrm{H}$ \\
\hline C5: History of threats & $\mathrm{ML}$ & $\mathrm{M}$ \\
\hline
\end{tabular}

Table 8. Importance Weight of Criterion Related to Impact of Threats

\begin{tabular}{|l|c|c|}
\hline & DM1 & DM2 \\
\hline \hline C6: Financial cost & ML & M \\
\hline C7: Time cost (lost) & MH & H \\
\hline C8: Credit cost & VL & VL \\
\hline C9: Human cost & VH & H \\
\hline
\end{tabular}

Table 9. The Ratings of the Three Threats of Digital Documents by Decision Makers Under All Criterions

\begin{tabular}{|c|c|c|c|}
\hline Criteria & Threat & DM1 & DM2 \\
\hline \multirow[t]{3}{*}{$\mathrm{C} 1$} & $\overline{\mathrm{T} 1}$ & $\bar{G}$ & $\bar{G}$ \\
\hline & $\mathrm{T} 2$ & G & G \\
\hline & T3 & MP & $\mathrm{F}$ \\
\hline \multirow[t]{3}{*}{$\mathrm{C} 2$} & $\mathrm{~T} 1$ & MG & G \\
\hline & $\mathrm{T} 2$ & G & MG \\
\hline & T3 & MP & MG \\
\hline \multirow[t]{3}{*}{$\mathrm{C} 3$} & $\mathrm{~T} 1$ & $\mathrm{~F}$ & G \\
\hline & $\mathrm{T} 2$ & MG & G \\
\hline & T3 & $\mathrm{P}$ & $P$ \\
\hline \multirow[t]{3}{*}{$\mathrm{C} 4$} & $\mathrm{~T} 1$ & $\mathrm{~F}$ & MG \\
\hline & $\mathrm{T} 2$ & MP & $\mathrm{P}$ \\
\hline & $\mathrm{T} 3$ & MG & G \\
\hline \multirow[t]{3}{*}{$\mathrm{C} 5$} & $\mathrm{~T} 1$ & MP & $\mathrm{P}$ \\
\hline & $\mathrm{T} 2$ & MP & MP \\
\hline & T3 & VP & VP \\
\hline \multirow[t]{3}{*}{ C6 } & $\mathrm{T} 1$ & MP & MP \\
\hline & $\mathrm{T} 2$ & MP & MP \\
\hline & T3 & MG & $\mathrm{F}$ \\
\hline \multirow[t]{3}{*}{$\mathrm{C} 7$} & $\mathrm{~T} 1$ & G & MG \\
\hline & $\mathrm{T} 2$ & MG & G \\
\hline & T3 & G & VG \\
\hline \multirow[t]{3}{*}{$\mathrm{C} 8$} & $\mathrm{~T} 1$ & $\mathrm{P}$ & $\mathrm{P}$ \\
\hline & $\mathrm{T} 2$ & $\mathrm{P}$ & MP \\
\hline & T3 & $\mathrm{MG}$ & MG \\
\hline \multirow[t]{3}{*}{ C9 } & $\mathrm{T} 1$ & VG & G \\
\hline & $\mathrm{T} 2$ & VG & MG \\
\hline & T3 & $\mathrm{VG}$ & MG \\
\hline
\end{tabular}


decision matrix and fuzzy weights of likelihood and impact of threats in digital documents domain. These tables are based on Tables 7-9, using the conversion of the linguistic evaluation into triangular fuzzy numbers (Step4). As mentioned in Step 5, after constructing the fuzzy decision matrix, we have to create the normalized fuzzy decision matrix as Tables $\mathbf{1 2}$ and $\mathbf{1 3}$. The results of Step 6 is related to deffuzification of combined weights as shown in these tables. Tables $\mathbf{1 4}$ and $\mathbf{1 5}$ show the weight matrices obtained based on the SAW method by multiplying each fuzzy value of Tables 12 and 13 with the related criterion weight (Step 7). We can calculate the value of likelihood and impact of each threat by adding all values related to each criterion, as in Tables $\mathbf{1 6}$ and $\mathbf{1 7}$. The probability of a threat occurring in

Table 10. The Fuzzy Decision Matrix and Fuzzy Weights of Threats Likelihood in Digital Documents Domain

\begin{tabular}{|c|c|c|c|c|c|}
\hline & C1 & C2 & C3 & C4 & C5 \\
\hline \hline Weight & $(0.7,0.9,1)$ & $(0.6,0.8,0.95)$ & $(0.5,0.7,0.9)$ & $(0.4,0.6,0.75)$ & $(0.2,0.4,0.6)$ \\
\hline T1 & $(7,9,10)$ & $(6,8,9.5)$ & $(5,7,8.5)$ & $(4,6,8)$ & $(0.5,2,4)$ \\
\hline T2 & $(7,9,10)$ & $(6,8,9.5)$ & $(6,8,9.5)$ & $(0.5,2,4)$ & $(1,3,5)$ \\
\hline T3 & $(2,4,6)$ & $(3,5,7)$ & $(0,1,3)$ & $(6,8,9.5)$ & $(0,0,1)$ \\
\hline
\end{tabular}

Table 11. The Fuzzy Decision Matrix and Fuzzy Weights of Threats Impact in Digital Documents Domain

\begin{tabular}{|c|c|c|c|c|}
\hline & C6 & C7 & C8 & C9 \\
\hline \hline Weight & $(0.2,0.4,0.6)$ & $(0.6,0.8,0.95)$ & $(0,0,0.1)$ & $(0.8,0.95,1)$ \\
\hline T1 & $(1,3,5)$ & $(6,8,9.5)$ & $(0,1,3)$ & $(8,9.5,10)$ \\
\hline T2 & $(1,3,5)$ & $(6,8,9.5)$ & $(0.5,2,4)$ & $(7,8.5,9.5)$ \\
\hline T3 & $(4,6,8)$ & $(8,9.5,10)$ & $(5,7,9)$ & $(7,8.5,9.5)$ \\
\hline
\end{tabular}

Table 12. The Fuzzy Normalized Decision Matrix of Threats Likelihood in Digital Documents Domain

\begin{tabular}{|c|c|c|c|c|c|}
\hline & C1 & C2 & C3 & C4 & C5 \\
\hline \hline Weight & 0.26 & 0.23 & 0.21 & $(0.17$ & 0.12 \\
\hline $\mathrm{T} 1$ & $(0.7,0.9,1)$ & $(0.63,0.84,1)$ & $(0.53,0.74,0.89)$ & $(0.06,0.08,0.13)$ & $(0.1,0.4,0.8)$ \\
\hline $\mathrm{T} 2$ & $(0.7,0.9,1)$ & $(0.63,0.84,1)$ & $(0.63,0.84,1)$ & $(0.13,0.25,1)$ & $(0.2,0.6,1)$ \\
\hline $\mathrm{T} 3$ & $(0.2,0.4,0.6)$ & $(0.32,0.53,0.74)$ & $(0,0.11,0.32)$ & $(0.05,0.06 .0 .08)$ & $(0,0,0.2)$ \\
\hline
\end{tabular}

Table 13. The Fuzzy Normalized Decision Matrix of Threats Impact in Digital Documents Domain

\begin{tabular}{|c|c|c|c|c|}
\hline & C6 & C7 & C8 & C9 \\
\hline \hline Weight & 0.18 & 0.37 & 0.01 & 0.43 \\
\hline T1 & $(0.13,0.38,0.63)$ & $(0.6,0.8,0.95)$ & $(0,0.11,0.33)$ & $(0.8,0.95,1)$ \\
\hline T2 & $(0.13,0.38,0.63)$ & $(0.6,0.8,0.95)$ & $(0.06,0.22,0.44)$ & $(0.7,0.85,0.95)$ \\
\hline T3 & $(0.5,0.75,1)$ & $(0.8,0.95,1)$ & $(0.56,0.78,1)$ & $(0.7,0.85,0.95)$ \\
\hline
\end{tabular}

Table 14. The Fuzzy Weighted Normalized Decision Matrix of Threats Likelihood in Digital Documents Domain

\begin{tabular}{|c|c|c|c|c|c|}
\hline & C1 & C2 & C3 & C4 & C5 \\
\hline \hline $\mathrm{T} 1$ & $(0.18,0.23,0.26)$ & $(0.14,0.19,0.23)$ & $(0.11,0.15,0.18)$ & $(0.01,0.01,0.02)$ & $(0.01,0.05,0.1)$ \\
\hline $\mathrm{T} 2$ & $(0.18,0.23,0.26)$ & $(0.14,0.19,0.23)$ & $(0.13,0.18,0.21)$ & $(0.02,0.04,0.17)$ & $(0.02,0.07,0.12)$ \\
\hline $\mathrm{T} 3$ & $(0.05,0.1,0.16)$ & $(0.07,0.12,0.17)$ & $(0,0.02,0.07)$ & $(0,0.01 .0 .01)$ & $(0,0,0.02)$ \\
\hline
\end{tabular}


Table 15. The Fuzzy Weighted Normalized Decision Matrix of Threats Impact in Digital Documents Domain

\begin{tabular}{|c|c|c|c|c|}
\hline & C6 & C7 & C8 & C9 \\
\hline \hline $\mathrm{T} 1$ & $(0.02,0.07,0.11)$ & $(0.22,0.3,0.35)$ & $(0,0,0)$ & $(0.34,0.41,0.43)$ \\
\hline $\mathrm{T} 2$ & $(0.02,0.07,0.11)$ & $(0.22,0.3,0.35)$ & $(0,0,0)$ & $(0.3,0.36,0.41)$ \\
\hline $\mathrm{T} 3$ & $(0.09,0.13,0.18)$ & $(0.3,0.35,0.37)$ & $(0,0,0.01)$ & $(0.3,0.36,0.41)$ \\
\hline
\end{tabular}

digital documents domain is calculated in two phases as Table 18 illustrates: 1) multiplying the fuzzy values of likelihood and impact of each threat (Step 8): 2) Deffuzification of each fuzzy triangular with Signed Distance method (Step 9). Eventually, as Table 19 illustrates, the overall risk level of threats in digital document domain is calculated by multiplying the risk level of threat in number 83.6, which is the importance coefficient of digital document based on Table 5.

Table 16. The Value of Threats Likelihood in Digital Documents Domain as Fuzzy Numbers

\begin{tabular}{|c|c|}
\hline Threat & Fuzzy Triangular \\
\hline \hline $\mathrm{T} 1$ & $(0.45,0.63,0.79)$ \\
\hline $\mathrm{T} 2$ & $(0.49,0.71,0.99)$ \\
\hline $\mathrm{T} 3$ & $(0.12,0.25,0.43)$ \\
\hline
\end{tabular}

Table 17. The Value of Threats Impact in Digital Documents Domain as Fuzzy Numbers

\begin{tabular}{|c|c|}
\hline Threat & Fuzzy Triangular \\
\hline \hline $\mathrm{T} 1$ & $(0.58,0.7,0.89)$ \\
\hline $\mathrm{T} 2$ & $(0.54,0.73,0.87)$ \\
\hline $\mathrm{T} 3$ & $(0.69,0.84,0.97)$ \\
\hline
\end{tabular}

Based on Table 4, the risk level of all threats in digital document domain are between Medium and High-Low ranges. Thus, this domain does not present a critical risk. To verify the accuracy of the proposed model, we have compared the results with TOPSIS model. We have implemented the TOPSIS model and Table 20 illustrates this comparison. As seen in Table 20, our model has the same results. To get better results, we got help from different experts for each threat and domain.

Table 18. The Probability of Threat Occurring in Digital Documents Domain as Fuzzy

\begin{tabular}{|c|c|c|}
\hline Threat & $\begin{array}{c}\text { Fuzzification Values } \\
\text { of Risk Level }\end{array}$ & $\begin{array}{c}\text { Defuzzification } \\
\text { Values }\end{array}$ \\
\hline \hline $\mathrm{T} 1$ & $(0.26,0.44,0.7)$ & 0.46 \\
\hline $\mathrm{T} 2$ & $(0.26,0.52,0.86)$ & 0.54 \\
\hline $\mathrm{T} 3$ & $(0.08,0.21,0.42)$ & 0.23 \\
\hline
\end{tabular}

Using this process, we can calculate the risk level of all threats related to the other domains. At the end of paper, the results for all domains are available. Table 29 shows all threats with the related risk level in ascending mode.

Table 19. Final Results of Risk Level in Digital Documents Domain in Ascending Mode

\begin{tabular}{|l|c|}
\hline \multicolumn{1}{|c|}{ Threat } & Risk Level \\
\hline \hline T2: Unauthorized copy or send & 45.14 \\
\hline T1: Unauthorized accessing & 38.46 \\
\hline T3: Unauthorized edit or delete & 19.23 \\
\hline
\end{tabular}

Table 20. Comparison of SAW and TOPSIS Methods

\begin{tabular}{|l|l|c|c|}
\hline \multicolumn{1}{|c|}{ Domain } & SAW & TOPSIS & Ratio (SAW/TOPSIS) \\
\hline \hline Communication services & 0.859 & 0.209 & 0.2431 \\
\hline Network services and communication infrastructures & 0.811 & 0.199 & 0.245 \\
\hline Informational services & 0.774 & 0.190 & 0.2451 \\
\hline Database & 0.765 & 0.189 & 0.2464 \\
\hline Hardware & 0.676 & 0.168 & 0.2491 \\
\hline Knowledge and skills of the personnel & 0.657 & 0.165 & 0.2507 \\
\hline Application software & 0.647 & 0.162 & 0.2509 \\
\hline Security equipments & 0.526 & 0.136 & 0.2583 \\
\hline Digital documents & 0.521 & 0.133 & 0.2558 \\
\hline
\end{tabular}


Table 21. Final Results of Risk Level in Communication Services Domain in Ascending Mode

\begin{tabular}{|l|c|c|}
\multicolumn{1}{|c|}{ Threat } & $\begin{array}{c}\text { Defuzzification } \\
\text { Value }\end{array}$ & Risk Level \\
\hline \hline T4: Identity theft & 0.51755 & 71.31 \\
\hline $\begin{array}{l}\text { T5: Unauthorized } \\
\text { access to user emails }\end{array}$ & 0.37518 & 51.69 \\
\hline T6: Abuse of Service & 0.37329 & 51.43 \\
\hline T7: Dictionary attack & 0.24992 & 34.43 \\
\hline T8: DoS & 0.20551 & 28.32 \\
\hline T9: Spam & 0.19472 & 26.83 \\
\hline T10: Malicious code & 0.16933 & 23.33 \\
\hline
\end{tabular}

Table 22. Final Results of Risk Level in Network Services and Communication Infrastructures Domain in Ascending Mode

\begin{tabular}{|l|c|c|}
\hline \multicolumn{1}{|c|}{ Threat } & $\begin{array}{c}\text { Defuzzification } \\
\text { Value }\end{array}$ & Risk Level \\
\hline \hline T11: Communication disruption & 0.35724 & 46.43 \\
\hline T12: Back door in system & 0.35137 & 45.67 \\
\hline T13: DoS & 0.34288 & 44.57 \\
\hline T14: Man-in-the-middle Attack & 0.31608 & 41.08 \\
\hline $\begin{array}{l}\text { T15: Damage to communication } \\
\text { lines }\end{array}$ & 0.3021 & 39.27 \\
\hline T16: Redirection Attack & 0.29629 & 38.51 \\
\hline T17: Sniffing & 0.26807 & 34.84 \\
\hline T18: Address theft & 0.25298 & 32.88 \\
\hline T19: Password cracking & 0.25231 & 32.8 \\
\hline T20: Service disruption & 0.246 & 31.98 \\
\hline $\begin{array}{l}\text { T21: Network hardware } \\
\text { technical problems }\end{array}$ & 0.24453 & 31.78 \\
\hline $\begin{array}{l}\text { T22: Network software } \\
\text { technical problems }\end{array}$ & 0.20071 & 26.09 \\
\hline T23: User errors & 0.17244 & 22.41 \\
\hline T24: Tunneling & 0.15447 & 20.08 \\
\hline
\end{tabular}

\section{CONCLUSION}

To implement an ISMS, we need a powerful tool to assess risks within an organization. In this paper, we proposed a fuzzy expert system to assess the risks of Information Systems. In the proposed model, a fuzzy technique was used to connect expert opinions with linguistic variables. These linguistic variables reflect the expert opinions more precisely. The distinct approach of this model, as compared to previous models, is that for determining the likelihood and impact of each threat, effective criterions for their measurement have been considered. Finally, experts present their opinions with respect to specific criterions leading us to increased accuracy and reliability of the results.

Table 23. Final Results of Risk Level in Informational Services Domain in Ascending Mode

\begin{tabular}{|c|c|c|}
\hline Threat & $\begin{array}{c}\text { Defuzzification } \\
\text { Value }\end{array}$ & $\begin{array}{r}\text { Risk } \\
\text { Level }\end{array}$ \\
\hline T25: Access to send information & 0.60391 & 74.93 \\
\hline T26: SSI Injection & 0.60391 & 74.93 \\
\hline T27: SQL Injection & 0.60391 & 74.93 \\
\hline $\begin{array}{l}\text { T28: Predictable Resource } \\
\text { Location }\end{array}$ & 0.51165 & 63.49 \\
\hline $\begin{array}{l}\text { T29: Unauthorized update of } \\
\text { web page }\end{array}$ & 0.49939 & 61.96 \\
\hline T30: Cross-site Scripting & 0.48285 & 59.91 \\
\hline $\begin{array}{l}\text { T31: Unauthorized access to } \\
\text { information }\end{array}$ & 0.47178 & 58.54 \\
\hline $\begin{array}{l}\text { T32: Insufficient Session } \\
\text { Expiration }\end{array}$ & 0.45691 & 56.69 \\
\hline T33: XPath Injection & 0.45372 & 56.3 \\
\hline T34: OS Commanding & 0.43106 & 53.49 \\
\hline T35: Directory Indexing & 0.41741 & 51.79 \\
\hline T36: LDAP Injection & 0.19492 & 24.19 \\
\hline $\begin{array}{l}\text { T37: Loss of information on } \\
\text { Web site }\end{array}$ & 0.11234 & 13.94 \\
\hline
\end{tabular}

Table 24. Final Results of Risk Level in Database Domain in Ascending Mode

\begin{tabular}{|l|c|c|}
\hline \multicolumn{1}{|c|}{ Threat } & $\begin{array}{c}\text { Defuzzification } \\
\text { Value }\end{array}$ & $\begin{array}{c}\text { Risk } \\
\text { Level }\end{array}$ \\
\hline \hline $\begin{array}{l}\text { T38: Unauthorized change in } \\
\text { fields and tables }\end{array}$ & 0.419892 & 51.51 \\
\hline T39: Password cracking & 0.401368 & 49.24 \\
\hline T40: SQL Injection & 0.390258 & 47.87 \\
\hline $\begin{array}{l}\text { T41: Unauthorized access to } \\
\text { server }\end{array}$ & 0.333465 & 40.91 \\
\hline T42: Sniffing & 0.330791 & 40.58 \\
\hline T43: DoS & 0.301794 & 37.02 \\
\hline T44: Loss of information & 0.288905 & 35.44 \\
\hline T45: Software error & 0.145757 & 17.88 \\
\hline
\end{tabular}


Table 25. Final Results of Risk Level in Hardware Domain in Ascending Mode

\begin{tabular}{|c|c|c|}
\hline Threat & Defuzzification Value & Risk Level \\
\hline T46: Depreciation of storage media & 0.23892 & 25.9 \\
\hline T47: Earthquake & 0.22543 & 24.43 \\
\hline T48: Hardware theft & 0.15557 & 16.86 \\
\hline T49: Maintenance error & 0.14907 & 16.16 \\
\hline T50: Human error & 0.13287 & 14.4 \\
\hline T51: Power fluctuations & 0.11514 & 12.48 \\
\hline T52: Explosion & 0.10535 & 11.42 \\
\hline T53: Flood & 0.09788 & 10.61 \\
\hline T54: Unauthorized change to hardware settings & 0.07267 & 7.88 \\
\hline T55: Supply disruption & 0.05952 & 6.45 \\
\hline T56: Electromagnetic waves & 0.05775 & 6.26 \\
\hline T57: Unauthorized access to hardware or server room & 0.05772 & 6.26 \\
\hline T58: Air conditioning Problem & 0.05604 & 6.07 \\
\hline T59: Fire & 0.05028 & 5.45 \\
\hline T60: Pollution and dust & 0.03239 & 3.51 \\
\hline T61: Temperature & 0.03214 & 3.48 \\
\hline
\end{tabular}

Table 26. Final Results of Risk Level in Knowledge and Skills of the Personnel Domain in Ascending Mode

\begin{tabular}{|l|c|c|}
\hline \multicolumn{1}{|c|}{ Threat } & $\begin{array}{c}\text { Defuzzification } \\
\text { Value }\end{array}$ & $\begin{array}{c}\text { Risk } \\
\text { Level }\end{array}$ \\
\hline \hline T62: Dependency to personnel & 0.55518 & 58.51 \\
\hline $\begin{array}{l}\text { T63: Non-compliance with } \\
\text { regulations } \\
\text { concerning access level }\end{array}$ & 0.50665 & 53.39 \\
\hline T64: Theft & 0.43176 & 45.5 \\
\hline T65: Dissatisfied personnel & 0.40716 & 42.91 \\
\hline $\begin{array}{l}\text { T66: Shortage of skilled } \\
\text { personnel }\end{array}$ & 0.31012 & 32.68 \\
\hline T67: Human error & 0.15665 & 16.51 \\
\hline
\end{tabular}

Table 27. Final Results of Risk Level in Application Software Domain in Ascending Mode

\begin{tabular}{|l|c|c|}
\hline \multicolumn{1}{|c|}{ Threat } & $\begin{array}{c}\text { Defuzzification } \\
\text { Value }\end{array}$ & $\begin{array}{c}\text { Risk } \\
\text { Level }\end{array}$ \\
\hline \hline $\begin{array}{l}\text { T68: Unauthorized update of } \\
\text { information }\end{array}$ & 0.47564 & 49.35 \\
\hline T69: Damaging by malware tools & 0.4264 & 44.24 \\
\hline T70: Identity theft & 0.42509 & 44.11 \\
\hline $\begin{array}{l}\text { T71: Useing of the system in a } \\
\text { abusive way }\end{array}$ & 0.42499 & 44.1 \\
\hline
\end{tabular}

\begin{tabular}{|l|c|c|}
\multicolumn{1}{|c|}{ Threat } & $\begin{array}{c}\text { Defuzzification } \\
\text { Value }\end{array}$ & $\begin{array}{c}\text { Risk } \\
\text { Level }\end{array}$ \\
\hline \hline $\begin{array}{l}\text { T72: Unauthorized access to } \\
\text { software }\end{array}$ & 0.41248 & 42.8 \\
\hline $\begin{array}{l}\text { T73: Repudiation of working with } \\
\text { software }\end{array}$ & 0.36195 & 37.56 \\
\hline $\begin{array}{l}\text { T74: Entering false information } \\
\text { into the software }\end{array}$ & 0.31097 & 32.27 \\
\hline T75: Software error & 0.20707 & 21.49 \\
\hline T76: Human error in the software & 0.16083 & 16.69 \\
\hline
\end{tabular}

Table 28. Final Results of Risk Level in Security Equipments Domain in Ascending Mode

\begin{tabular}{|l|c|c|}
\hline \multicolumn{1}{|c|}{ Threat } & $\begin{array}{c}\text { Defuzzification } \\
\text { Value }\end{array}$ & $\begin{array}{c}\text { Risk } \\
\text { Level }\end{array}$ \\
\hline \hline T77: Bypass security controls & 0.485389 & 40.94 \\
\hline $\begin{array}{l}\text { T78: Unauthorized change to device } \\
\text { options }\end{array}$ & 0.313267 & 26.42 \\
\hline $\begin{array}{l}\text { T79: Unauthorized access to } \\
\text { information }\end{array}$ & 0.279961 & 23.61 \\
\hline T80: Device damage and failure & 0.236998 & 19.99 \\
\hline T81: Error on device performance & 0.146913 & 12.39 \\
\hline
\end{tabular}


Table 29. Risk Level of All Threats in All Domain in IT Section of a Supply Chain Management Company in Ascending Mode

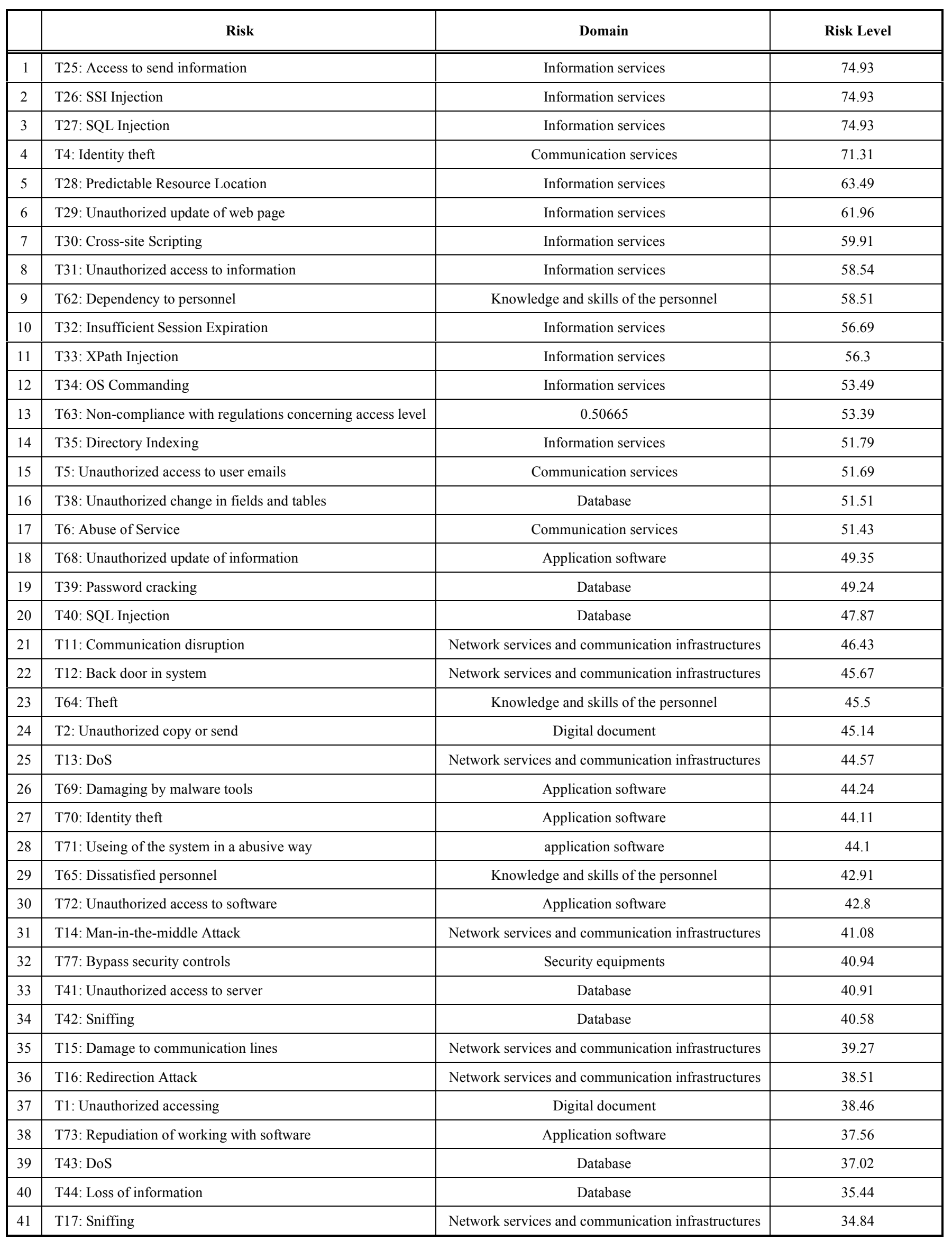




\begin{tabular}{|c|c|c|c|}
\hline & Risk & Domain & Risk Level \\
\hline 42 & T7: Dictionary attack & Communication services & 34.43 \\
\hline 43 & T18: Address theft & Network services and communication infrastructures & 32.88 \\
\hline 44 & T19: Password cracking & Network services and communication infrastructures & 32.8 \\
\hline 45 & T66: Shortage of skilled personnel & Knowledge and skills of the personnel & 32.68 \\
\hline 46 & T74: Entering false information into the software & Application software & 32.27 \\
\hline 47 & T20: Service disruption & Network services and communication infrastructures & 31.98 \\
\hline 48 & T21: Network hardware technical problems & Network services and communication infrastructures & 31.78 \\
\hline 49 & T8: DoS & Communication services & 28.32 \\
\hline 50 & T9: Spam & Communication services & 26.83 \\
\hline 51 & T78: Unauthorized change to device options & Security equipments & 26.42 \\
\hline 52 & T22: Network software technical problems & Network services and communication infrastructures & 26.09 \\
\hline 53 & T46: Depreciation of storage media & Hardware & 25.9 \\
\hline 54 & T47: Earthquake & Hardware & 24.43 \\
\hline 55 & T36: LDAP Injection & Information services & 24.19 \\
\hline 56 & T79: Unauthorized access to information & Security equipments & 23.61 \\
\hline 57 & T10: Malicious code & Communication services & 23.33 \\
\hline 58 & T23: User errors & Network services and communication infrastructures & 22.41 \\
\hline 59 & T75: Software error & Application software & 21.49 \\
\hline 60 & T24: Tunneling & Network services and communication infrastructures & 20.08 \\
\hline 61 & T80: Device damage and failure & Security equipments & 19.99 \\
\hline 62 & T3: Unauthorized edit or delete & Digital document & 19.23 \\
\hline 63 & T45: Software error & Database & 17.88 \\
\hline 64 & T48: Hardware theft & Hardware & 16.86 \\
\hline 65 & T76: Human error in the software & Application software & 16.69 \\
\hline 66 & T67: Human error & Knowledge and skills of the personnel & 16.51 \\
\hline 67 & T49: Maintenance error & Hardware & 16.16 \\
\hline 68 & T50: Human error & hardware & 14.4 \\
\hline 69 & T37: Loss of information on Web site & Information services & 13.94 \\
\hline 70 & T51: Power fluctuations & hardware & 12.48 \\
\hline 71 & T81: Error on device performance & Security equipments & 12.39 \\
\hline 72 & T52: Explosion & hardware & 11.42 \\
\hline 73 & T53: Flood & hardware & 10.61 \\
\hline 74 & T54: Unauthorized change to hardware settings & hardware & 7.88 \\
\hline 75 & T55: Supply disruption & hardware & 6.45 \\
\hline 76 & T56: Electromagnetic waves & hardware & 6.26 \\
\hline 77 & T57: Unauthorized access to hardware or server room & hardware & 6.26 \\
\hline 78 & T58: Air conditioning Problem & hardware & 6.07 \\
\hline 79 & T59: Fire & hardware & 5.45 \\
\hline 80 & T60: Pollution and dust & hardware & 3.51 \\
\hline 81 & T61: Temperature & hardware & 3.48 \\
\hline
\end{tabular}




\section{ACKNOWLEDGEMENT}

The support of the Natural Sciences and Engineering Research Council of Canada (NSERC) is gratefully acknowledged.

\section{CONFLICT OF INTEREST}

Declared none.

\section{REFERENCES}

[1] International Standard Organization, ISO/IEC 27005, Information Security Risk Management, 2008.

[2] G. Stoneburner, A. Goguen, and A. Feringa, "Risk management guide for information technology systems," 2002. [Online] Available: http://csrc.nist.gov/publications/nistpubs/800-30/sp80030.pdf .

[3] A. Shameli-Sendi, N. Ezzati-Jivan, M. Jabbarifar, and M. Dagenais, "Intrusion response systems: survey and taxonomy," Int. J. Comput. Sci. Netw.Secur., vol. 12, no. 1, pp.1-14, 2012.

[4] ENISA, "Risk Management: Implementation principles and Inventories for Risk Management/Risk Assessment methods and tools," Technical Department of European Network and Information Security Agency, 2006.

[5] L. Zadeh, "Fuzzy sets," Inf. Control., pp. 338-353, 1965.

[6] D. M. Zhao, J. H. Wang, and J.F. Ma, "Fuzzy Risk Assessment of Network Security," In: Fifth International Conference on Machine Learning and Cybernetics, Dalian: China, 2006, pp. 4400-4405.

[7] B. C. Guan, C. C. Lo, P. Wang, and J. S. Hwang, "Evaluation of information security related risk of an organization: the application of multi criteria decision making method," In: IEEE 37th Annual International Carnahan Conference, Taipei: Taiwan,2003, pp. 168175.

[8] C. L. Hwang and K. Yoon, Multiple Attribute Decision Making Method and Applications, SpringerVerlag: New York, 1981.

[9] S. Y. Chou, Y. H. Chang, and C. Y. Shen, "A fuzzy simple additive weighting system under group decision-making for facility location selection with objective/subjective attributes," Oper.Res., vol. 189, pp.132-145, 2008.

[10] Y. M. Wang and T. M. Elhag, "Fuzzy TOPSIS method based on alpha level sets with an application to bridge risk assessment," Expert Sys. Appl., pp. 309-319, 2006.

[11] K. Haslum, A. Abraham, and S. Knapskog, "Fuzzy Online Risk Assessment for Distributed Intrusion Prediction and Prevention Systems," In: Tenth International Conference on Computer Modeling and Simulation, Cambridge: IEEE Computer Society Press, 2008, pp. 216-223.

[12] A. Shameli-Sendi, M. Jabbarifar, M. Shajari, and M. Dagenais, "FEMRA: Fuzzy Expert Model for Risk Assessment," In: Fifth International Conference on Internet Monitoring and Protection, Barcelona: Spain, 2010, pp. 48-53.

[13] A. Kaufmann and M. M. Gupta, Introduction to Fuzzy Arithmetic: Theory and Applications, Van Nostrand Reinhold: New York, 1985 .

[14] J. S. Yao and J. Chiang, "Inventory without backorder with fuzzy total cost and fuzzy storing cost defuzzified by centroid and signed distance," Oper. Res., vol. 148, pp. 401-409, 2003.

[15] J. S. Yao and K. Wu, "Ranking fuzzy numbers based on decomposition principle and signed distance," Fuzzy Set Syst., vol. 116, pp. $75-88,2000$

[16] S. H. Ghyym, "A semi linguistic fuzzy approach to multi actor decision making: application to aggregation of experts' judgments," Ann. Nucl. Energy, vol. 26, pp. 1097-1112, 1999.

[17] Web Application Security Consortium: Threat Classification. Available: http://www.webappsec.org/projects/threat .

[18] D. J. Landoll, "The security Risk Assessment Handbook," Auerbach Publications: USA, 2006

[19] C. T. Chen, "A fuzzy approach to select the location of the distribution center," Fuzzy Set Syst., vol. 118, pp. 65-73, 2001.

[20] National Institute of Standards and Technology (NIST), Special Publication 800-12, An Introduction to Computer Security:The NIST Handbook, 1995

[21] International Standard Organization, ISO/IEC TR 15446, Information technology - Security techniques - Guide for the production of Protection Profiles and Security Targets, 2004.

(C) Shameli-Sendi et al.; Licensee Bentham Open.

This is an open access article licensed under the terms of the Creative Commons Attribution Non-Commercial License (http://creativecommons.org/licenses/ by-nc/3.0/) which permits unrestricted, non-commercial use, distribution and reproduction in any medium, provided the work is properly cited. 